\title{
Design of Flying-Bird Type Cable Stayed Arch Bridge with Three- Leaf Rose Shaped CFST Arch Rib
}

\author{
Weisheng Wang ${ }^{1 *}$ and Jilin Wang ${ }^{1}$ \\ ${ }^{1}$ China Design Group Co., Ltd, Nanjing, China,210007
}

\begin{abstract}
According to the geometric figure of three-leaf rose curve, this paper puts forward a flying-bird type cable-stayed arch bridge with three-leaf rose curve shaped CFST arch rib, which has beautiful appearance and one bridge leads to three banks. The space cables are set between the three-leaf rose linear space arch ribs to resist negative bending moment, and the tie cables are set between the arch feet to resist positive bending moment. On the inclined pylon at the tail of the flying-bird type cable-stayed arch bridge, the stay-cables are arranged to balance the arch thrust, and the suspension-cables are arranged on the three leaf rose linear spatial arch ribs to hang the three fork bridge deck. The flying-bird type cable-stayed arch bridge with three-leaf rose linear CFST arch rib adopts spatial cable structure system, which has good structural stability.Combined with the actual project, the engineering parameters are designed, the Midas finite element analysis model is established, the internal force analysis and modal analysis are carried out, and the rationality of flying-bird type cable-stayed arch bridge with three-leaf rose linear CFST arch rib is verified.
\end{abstract}

\section{Introduction}

The Midland fork bridge in Michigan, USA, was built in 1981. It spans the intersection of the Chippewa river and the Tittabawassee river. The convenient transportation and unique shape make the bridge a famous local landscape.

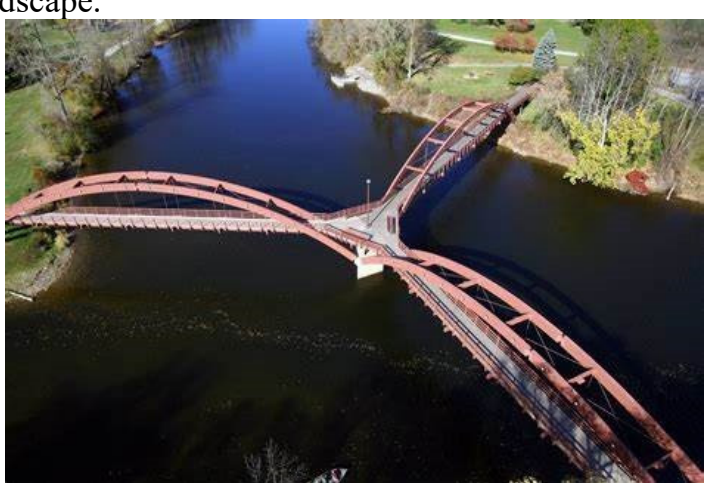

Figure 1. Midland fork bridge

According to the landform of three-rivers-confluence, the structural shape of clover and the mathematical equation of three-leaf rose line, the design scheme of concrete filled steel tube flying swallow type cable-stayed arch bridge structure is adopted, and the stiffening beam of three fork highway bridge deck is suspended by suspension cable.

This paper studies the configuration of the three-leaf rose shaped CFST flying swallow type cable-stayed arch bridge, designs the engineering parameters, establishes the Midas finite element model, carries out the dynamic modal research, and demonstrates the structural rationality of the three fork shaped concrete-filled steel tube flying swallow type cable-stayed arch bridge in many aspects.

\section{Configuration study}

The arch rib of the three leaf rose line flying swallow type cable-stayed arch bridge is a three-dimensional spatial arch rib, and its plane forward projection is a three leaf rose line figure, and the side elevation projection of the arch rib is cosine function. According to the flying swallow type cable-stayed arch bridge, the threedimensional space arch rib is bent and warped at the arch foot to form the cable-stayed bridge tower.

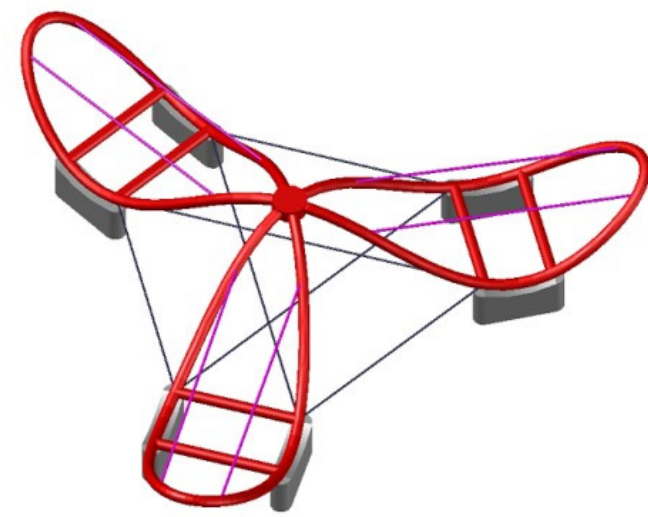

Figure 2. Three-leaf rose line spatial arch rib

Trefoil rose line is an important figure in mathematics, the mathematical expression is as follows:

$$
\rho=\mathrm{a} \cdot \cos (3 \theta)
$$

\footnotetext{
*Wang Weisheng: 289200225@qq.com
} 
Where: parameter a is the envelope radius, which controls the length of the rose line leaves.

The three leaf rose line flying swallow type cablestayed arch rib is installed with tie bar cable, and the cable between the arch ribs is installed to form a whole structure. After floating and dragging across the river, the sling is installed. The three leaf rose line flying swallow type cable-stayed arch rib suspends the three fork bridge deck, forming a three fork shaped steel tube concrete flying swallow type cable-stayed arch bridge structure.

The three branch concrete-filled steel tube flying swallow type cable-stayed arch bridge skillfully uses the trefoil rose line to construct the cable-stayed arch bridge, which has unique shape and beautiful shape. With smooth and convenient traffic and coordinated with the environment of three-rivers-confluence, it will become a beautiful scenic line in three-rivers-confluence. The self balanced structure system of flying-swallow type cablestayed arch bridge is formed by setting the tie bar of flying-swallow arch bridge and the cable between arch ribs to balance the support thrust of arch bridge and greatly improve the structural stiffness. The scheme of dragging across the river simplifies the construction and is economical.

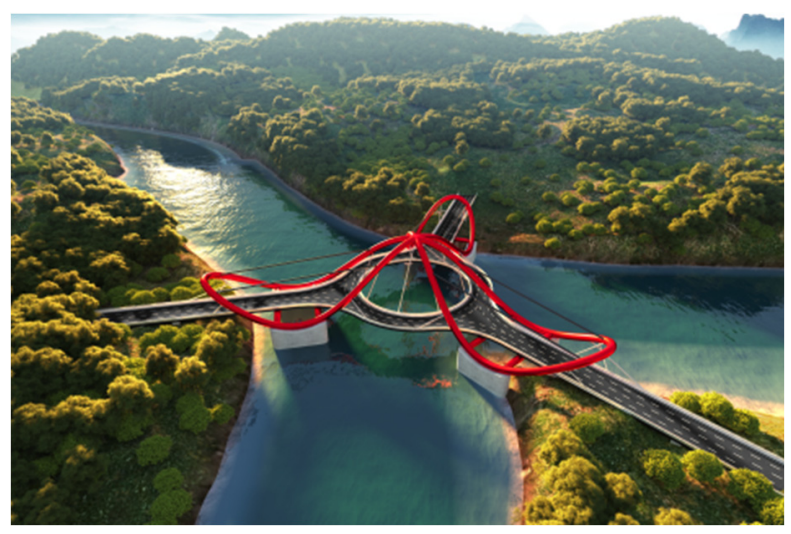

Figure 3. Three fork flying swallow cable stayed arch bridge

\section{Parameter design}

Three-fork bridge is a three-leaf rose shaped concretefilled steel tube flying swallow type cable-stayed arch bridge. Its plane orthographic projection is a three-leaf rose line figure, the side elevation projection of the arch rib is a cosine function, and the envelope diameter of the three leaf rose line spatial arch rib is 200 meters.

Three leaf rose line spatial arch rib adopts reinforced concrete structure, the side elevation projection of arch rib is cosine function, the distance from the center point to the support is 60 meters, the 40 meter interval section after the support point is warped to form an arch cable-stayed bridge tower. The diameter of steel pipe is 2.5 meters, the wall thickness of steel pipe is $20 \mathrm{~mm}$, and C40 concrete is poured inside, and the rise span ratio of arch rib is $1 / 4$.

Ring section lane is set in the center of three-fork bridge. The inner diameter of the ring is $40 \mathrm{~m}$, the ring lane is 3 lanes, the bridge deck width is $12 \mathrm{M}$, the straight section is 4 lanes, and the bridge deck width of straight section is $16 \mathrm{M}$. the circular section transition is adopted between the straight section and the circular section. The deck of three-fork bridge is steel box girder with a beam height of $1.5 \mathrm{~m}$.

The cable is set in the middle of the three fork concrete-filled steel tube flying swallow type cable-stayed arch bridge, and the cable-stayed cable is set at the tail to suspend the three branch stiffening beam bridge surface. The sling and cable-stayed are made of 1670mpa galvanized high-strength steel wire. The diameter of the sling and cable-stayed cable are $0.3 \mathrm{~m}$, the sling spacing is $20 \mathrm{~m}$, and the cable-stayed spacing is $16 \mathrm{~m}$.

There are six cables between the central arch rib and the cable-stayed bridge tower of the triple fork concretefilled steel tube flying swallow type cable-stayed arch, one on the left and one on the left. The arch rib cable is made of 1670mpa galvanized high-strength steel wire, and the diameter of the cable is $0.5 \mathrm{~m}$. The cable is set to form the cable-stayed arch bridge structure system, reduce the unbalanced internal force of the support and improve the rigidity of the flying swallow type cable-stayed arch structure.

A total of 6 tied cables are set between the arch foot supports of the three branch concrete-filled steel tube flying swallow type cable-stayed arch. The cable at the arch rib foot adopts 1670mpa galvanized high-strength steel wire, and the diameter of the arch foot cable is $0.5 \mathrm{~m}$. The tie bar cable is set to form a flying swallow type arch bridge structure, which can reduce the unbalanced internal force of the support and improve the bearing capacity of the three fork shaped concrete-filled steel tube arch bridge.

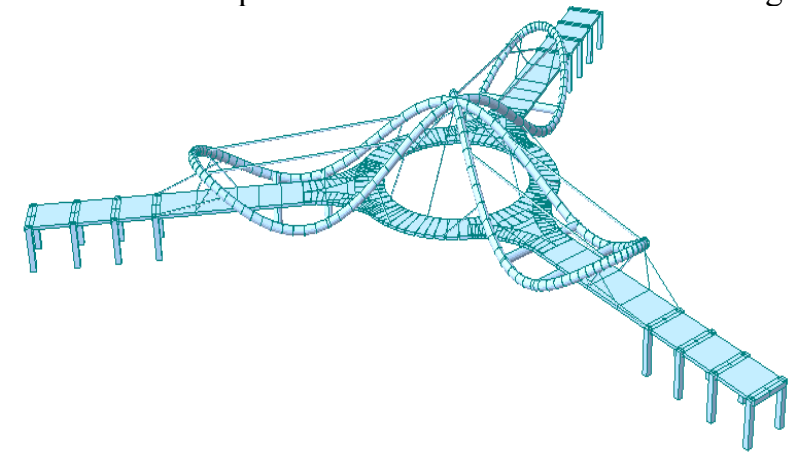

Figure 4. Midas model

\section{Numerical analysis under vertical load}

The bridge deck of main span is loaded with full load, the standard value of uniform load $5 \mathrm{kn} / \mathrm{m} 2$ is adopted for additional dead load of bridge deck, and standard value of highway first-class load is adopted for bridge deck live load. The calculation results are as follows:

The calculation results are as follows:

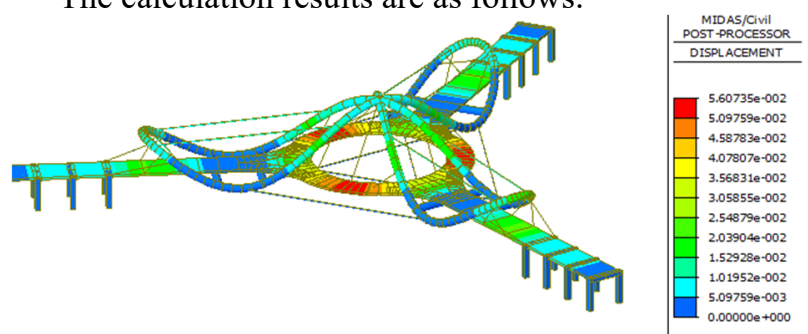

Figure 5. Calculation results of displacement under vertical load (dead load+live load) 


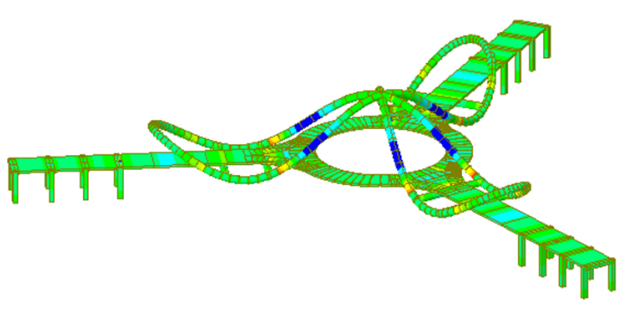

(a) Internal force of beam element

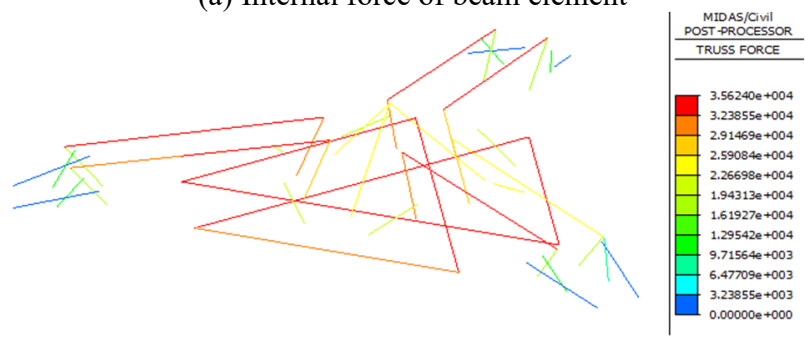

(b) Stress of cable element

Figure 6. Internal force calculation result(dead load+live load)

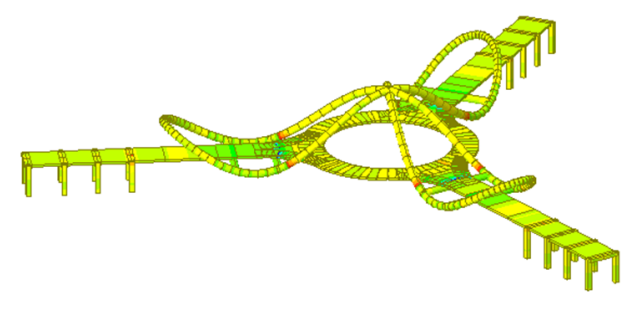

(a) Internal force of beam element

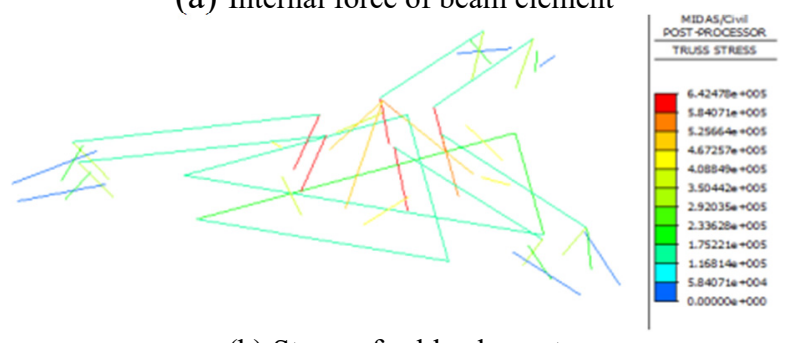

(b) Stress of cable element

Figure 7. Stress calculation results (dead load+live load)

The maximum vertical displacement occurs in the middle of the span, and the maximum displacement is $0.036 \mathrm{~m}$, which meets the requirement of $1 / 500$ limit specified in the code.

The maximum internal force of the cable is $35624.0 \mathrm{kn}$, and the maximum stress of the cable is $642.5 \mathrm{mpa}$, which meets the strength requirements. The maximum internal force of bridge arch is $325721 \mathrm{kn}$, and the maximum stress of bridge arch is $89.3 \mathrm{mpa}$, which meets the strength requirements. The concrete-filled steel tube, $\mathrm{C} 40$ concrete and q355 steel can meet the strength requirements.

\section{Dynamic modal analysis}

Based on Midas's nonlinear static analysis and modal analysis function, the natural vibration characteristics are analyzed. In order to avoid omitting any vibration mode, the sub block method is used to solve the characteristic equation.

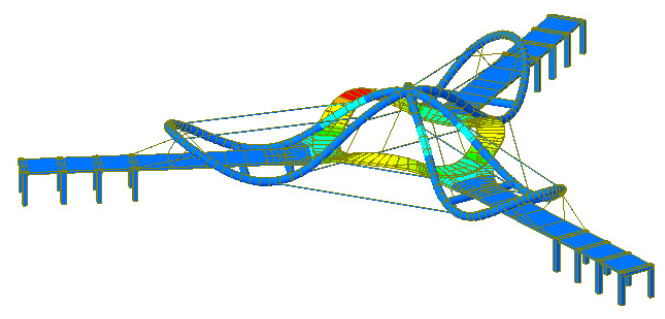

(a) 1 st order mode $(2.037 \mathrm{HZ})$

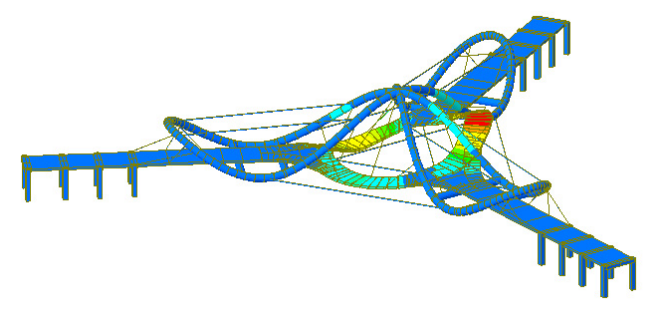

(b) 2 st order mode $(2.062 \mathrm{~Hz} \mathrm{HZ})$

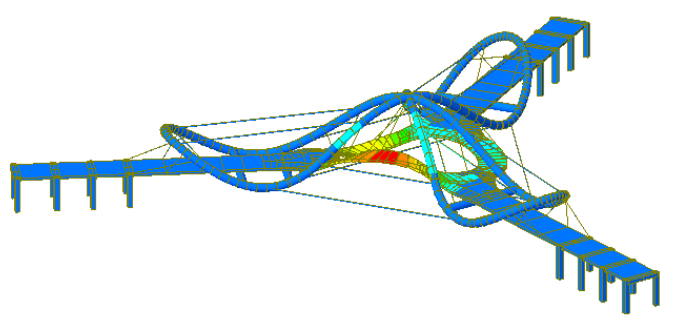

(c) 3 st order mode $(2.093 \mathrm{HZ})$

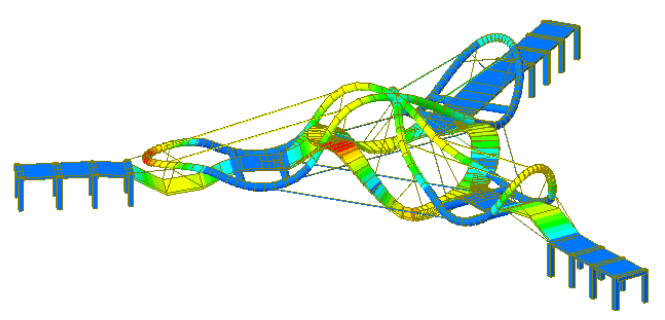

(d) 4 st order mode $(2.693 \mathrm{HZ})$

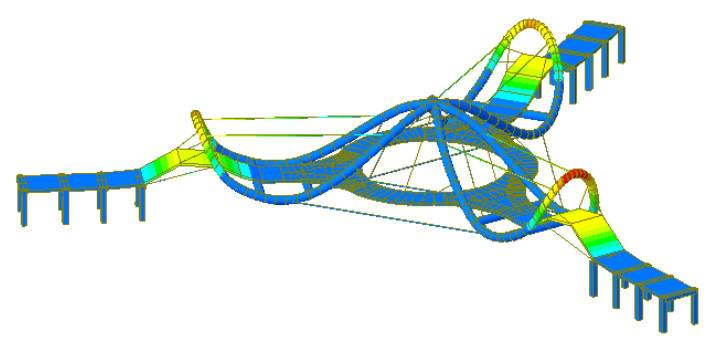

(e) 6 st order mode $(2.87 \mathrm{HZ})$

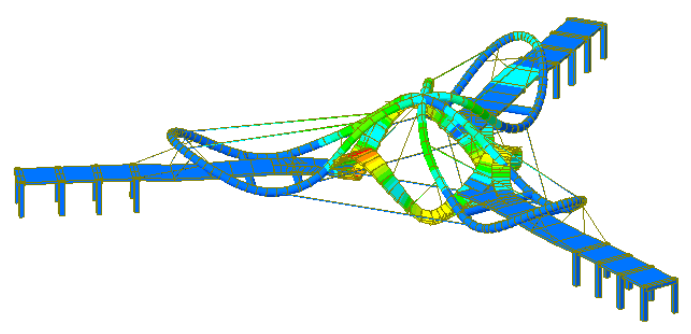

(f) 9 st order mode $(3.314 \mathrm{HZ})$

Figure 8. Dynamic mode 
It can be seen from the calculation results in the above figure that the first mode is positive symmetrical side bending with frequency of $2.037 \mathrm{hz}$; the ninth mode is torsional mode with frequency of $3.314 \mathrm{hz}$.

On the whole, the vibration modes are dense, and obvious mode grouping phenomenon occurs. The first eight modes are mainly lateral bending and vertical bending vibration, and the positive symmetric torsional vibration mode does not appear until the ninth order. The torsion to bending frequency ratio of 1.63 is higher, and the wind resistance stability of the structure is better.

The triple fork shaped CFST flying swallow type cable-stayed arch bridge, with three legs, greatly improves the structural stability of the arch bridge and has good wind resistance stability.

\section{Conclusion}

In this paper, the configuration of three fork flying swallow type cable-stayed arch bridge is studied, the Midas finite element model is established, the calculation and analysis under vertical load are carried out, and the dynamic modal analysis is carried out

(1) A new type of three leaf rose shaped concrete-filled steel tubular flying swallow type cable-stayed arch bridge is proposed. Its plane orthographic projection is three-fork rose line figure, and the side elevation projection of arch rib is cosine function, which has unique shape and convenient transportation.

(2) Space cables are set between the three-leaf rose linear spatial arch ribs, and tie bar cables are set between the arch feet to facilitate the floating and dragging across the river. The suspension cables are suspended on the three bifurcated bridge deck, and the cable-stayed cables are set at the tail to form a space cable system. The thrust force of the middle arch and the reverse thrust of the tail warped cable-stayed arch bridge tower are balanced each other, forming a self balancing structural system, eliminating the unbalanced internal force of the support.

(3) The maximum vertical displacement occurs in the middle of the span, and the maximum displacement is $0.036 \mathrm{~m}$, which meets the requirement of $1 / 500$ limit specified in the code. The maximum internal force of the cable is $35624.0 \mathrm{kn}$, and the maximum stress of the cable is $642.5 \mathrm{mpa}$, which meets the strength requirements.

(4) The first eight vibration modes are mainly lateral bending and vertical bending vibration, and positive symmetry torsional vibration mode does not appear until the ninth order. The torsion to bending frequency ratio of 1.63 is higher, and the wind resistance stability of the structure is better.

\section{References}

1. Yiming, J.,Sanyuan, Z., Generalized rose line and its application [J]. Computer application research, 2004 (03): 170-171 (in Chinese)

2. Zhongfu, Y., Research on the horizontal thrust balance effect of tie bar on arch foot of flying swallow type concrete filled steel tube arch bridge [D]. Shaanxi: Chang'an University, 2009 (in Chinese)
3. Zong Z H, Jaistli B, Ge J P-Dynamic analysis ofa half-through Concrete-filled steel tubular arch bridge[J].Engineering structures.2005.

4. Yong, W., Mechanical analysis and experimental verification of special-shaped concrete filled steel tube arch bridge [D]. Sichuan: Southwest Jiaotong University, 2014(in Chinese)

5. Morcous, G., Hanna, K., Deng, Y., \& Tadros, M. K. . Concrete-Filled Steel Tubular Tied Arch Bridge System: Application to Columbus Viaduct[J]. JOURNAL OF BRIDGE ENGINEERING, 1, 107. 2012.

6. Lei Z.,Xinxin H., Experimental study on natural vibration characteristics and dynamic response of cable-stayed flying swallow arch bridge [J]. Building engineering technology and design, 2015, (9): 11981198(in Chinese)

7. Min P., optimization of design parameters of cable stayed arch bridge [D]. Hunan: Hunan University of science and technology, 2008(in Chinese)

8. .Nakamura, S., Tanaka, H., \& Kato, K. . Static analysis of cable-stayed bridge with CFT arch ribs [J]. Journal of Constructional Steel Research, 65(4), 776783.2009 . 